Historic, Archive Document

Do not assume content reflects current scientific knowledge, policies, or practices. 



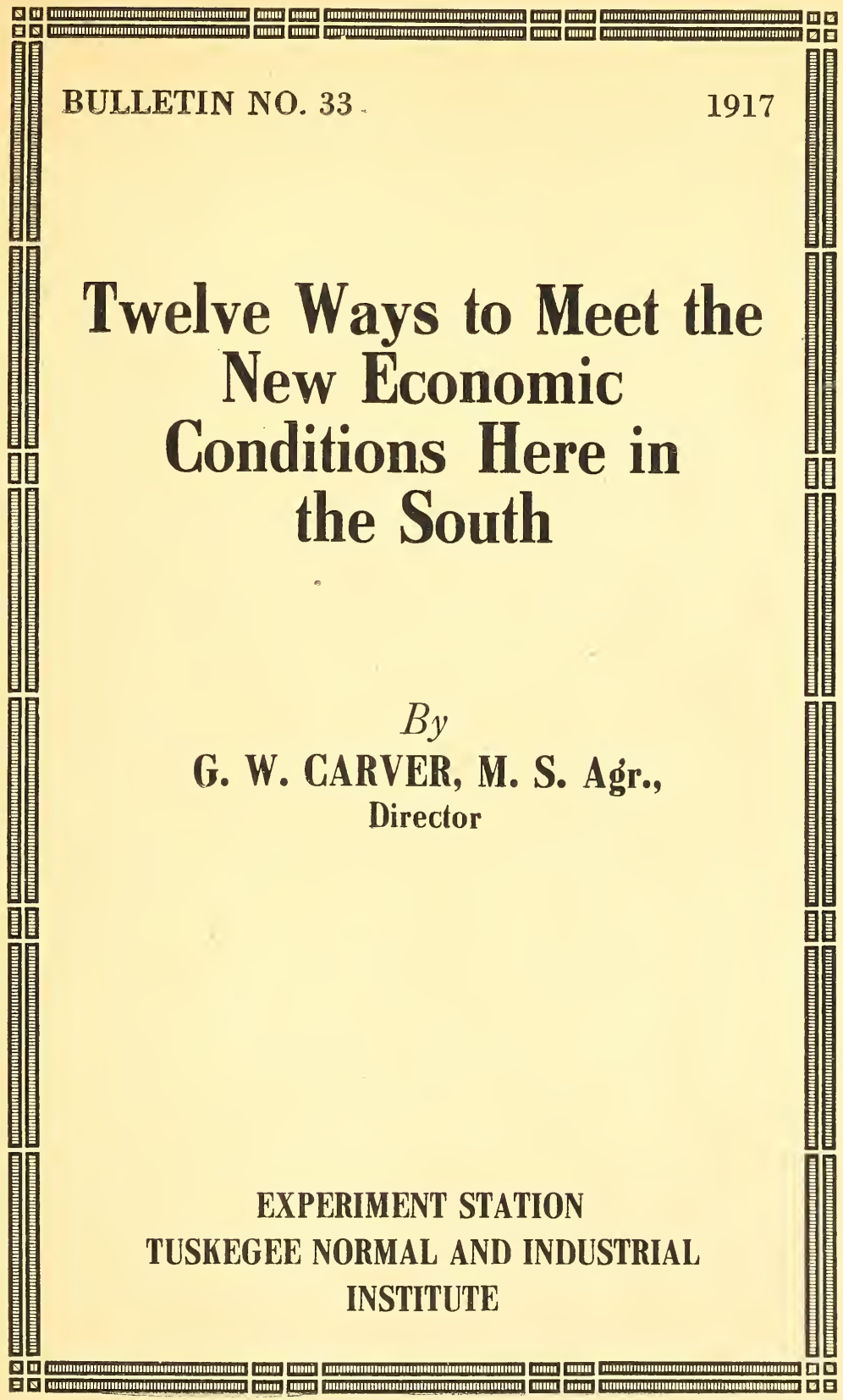





\title{
TWELVE WAYS TO MEET THE NEW ECONOMIC CONDITIONS HERE IN THE SOUTH
}

\author{
By G. W. CARVER
}

It needs but little or no discussion to convince us that we are on the beginning of the most perplexing, most interesting, and the most important period of our lives.

We are confronted with new economic conditions; the problems of last year are not the problems of this year; yea, the problems of yesterday are greatly overshadowed by the problems of today; and even the wisest heads are slow even to conjecture what will be the result, and where coming events will cast their shadows.

However, we are very conscious of the following questions, which stand up before us demanding an answer:

\section{QUESTION-1}

What shall I do with the boll weevil? In all probability it is here to stay.

Answer-Yes, the weevil is here, but our experiments prove that it may be controlled as follows:

(a) Prepare all land good and deep with a two-horse plow.

(b) Fertilize well.

(c) Plant an early variety of seed.

(d) Make rows a foot wider than is customary, and give the plants twice the distance in the drill.

(e) Stir the ground often to keep the cotton growing.

(f) Pick up squares and pick off weevils until the bottom and middle crops are made. Then stop picking off weevil. This will be about the middle of July or the first of August in this locality.

(g) Pick as fast as it opens.

(h) When through gathering the bottom and middle crops, destroy the stalks at once, and sow the field in a grain crop, such as oats, rye, wheat, barley, etc; and if for hay only, mix one-fourth of hairy vetch seed to three-fourths of any one of the above grains. 
(i) Clean off and burn all the rubbish from ditch banks, fence corners, and waste places, as the old weevils hide in these places and winter over.

(j) Encourage your neighbors to do the same. In this way the weevil will be reduced to starvation; so much so that the problem of control will be easy.

\section{QUESTION-2}

What shall we do for fertilizer? Potash is so high that it is out of the question, nitrate of soda but little better, and cotton seed selling for $\$ 64.00$ per ton; so the meal will be both scarce and too costly to use as fertilizer.

Answer-There are many thousands of tons of the finest fertilizers going to waste all over the South, in the form of desaying leaves of the forest and the rich sediment of the swamp, known as muck. Every idle moment from now until planting time should be put in gathering up these fertilizers. Make the mixture (compost) as follows :

(a) Build pen to hold as much as you wish.

(b) Spread two wagon-loads of muck and leaves over the bottom of the pen; then one load of barnyard manure; build up in this way until the pen is full.

(c) Put a rough shed over it sufficient to turn the bulk of water from heavy rains, or mound up like a potato hill. This is to prevent the excess of water from washing out the fertilizing constituents.

(d) Put into this compost-heap all the wood ashes, old plaster, waste lime, rags, paper, or any matter that will decay quickly. Bones beaten up fine are also excellent. If you cannot get the barnyard manure make the compost without it. You will be agreeably surprised at the increased yield of crops of all kinds.

(e) Break land deep ( 8 to 9 inches) and thorough; lay off rows with a middle-burster or two-horse plow; put compost in drill at the rate of 20 tons to the acre on medium land, and 25 tons to the acre on very poor land; plant direstly on the fertilizer; cultivate in the usual manner.

Results-The Experiment Station has had no commercial fertilizer put upon it for 12 years-nothing but the above compost and the proper rotation of crops. This year, 282 pounds of lint cotton, 45 bushels of corn, and 215 bushels of sweet potatoes were raised per acre.

\section{QUESTION-3}

Should the farmer keep a cow?

Answer-Yes, every farmer should keep one or two good cows; a 
good cow is half of any family's living, as she will furnish all the butter, milk, cream, etc., that the ordinary family can use, and if properly cared for a surplus can be had to sell. There are a number of foods that are more palatable, more healthy, and more economical when seasoned with milk and butter than when seasoned with lard or any other kind of shortening. Good bread, rich milk, and nice butter furnish almost a complete balanced ration.

\section{QUESTION-4}

Should a farmer raise chickens?

Answer-Yes, by all means every farmer should start with 12 good hens and one roosier. With a little care they will furnish all the eggs needed in the family, some meat, and a surplus at times to exchange for clothing and other necessities. A few guineas, ducks, turkeys, and a pair or two of geese will bring in much pleasure and profit at practically no cash outlay.

\section{QUESTION-5}

Should a farmer have a garden?

Ansuer-Yes, nothing will pay him better. It is one of the greatest money-makers on the farm. It makes money in two principal ways.

(a) It furnishes a great variety of foodstuff, which is absolutely essential to good health and the proper strength of both mind and bcdy. If we eat plenty of good, well-cooked vegetables every day, all other things being equal, we can do more work and better work than if we did not. We shall not get so tired, weary, and have to consult the doctor so often, and pay ou' such heavy doctor bills.

(b) In the garden there should always be a surplus of something to sell, especially of beans, peas, melons, onions, white and sweet potatoes, tomatoes, cabbage, turnips, rutabagas, rape, pumpkins, beets, squash, e.c., etc. The garden should furnish many things for canning, pickling, and preserving.

\section{QUESTION-6}

\section{Should a farmer try to raise fruit?}

Answer-Yes, fruit is an absolute necessity in the diet. No person can remain strong and vigorous in mind and body very long who neglects to make fruit of some kind a part of the daily diet. Every farmer should have a few peach, pear, plum, fig, and apple trees on his place; also grape vines, strawberries, etc. A few trees and bushes well cared for will furnish sufficient fruit for the needs of the family. Nut trees such as pecans, walnuts, chestnuts, hickory nuts, etc., are 
fine shade trees, and the nuts are becoming more and more a part of the diet, taking the place of meat.

\section{QUESTION-7}

Should a farmer raise hogs?

Answer-Yes, for the following reasons:

(a) No other animal converts into meat so much foodstuff that would otherwise go to waste.

(b) They will furnish us all of our meat, lard, and the many other choice dainties that no other meat is so popular in supplying.

(c) There is a great demand for hogs at all times; the demand is always greater than the supply. They are sure mortgage lifters, and will pay any farmer out of debt if he will give them a chance.

(d) Hogs are easily raised; they will eat and thrive on weeds, nuts, and fruits of most any kind. These, however, are especially good: wild primrose, smooth and thorny careless weeds (pig weeds), purslane (pusley), wild plums, acorns, beechnuts, nutgrass, etc.

The following choice foods can be easily grown: Sweet potatoes, sorghum millet, corn, peanuts, velvet beans, rape, collards, cabbage, turnips, beets, pumpkins, cow peas, soja beans, Bermuda grass; also wheat, rye, oats, burr and crimson clover for winter pasture.

\section{QUESTION-8}

Should a farmer try to raise stock?

Answer-Yes, every bit that he possibly can. In addition to those mentioned he should have mares that would bring colts every year. With proper care they will do all the farm work and raise the-colts too. A few sheep, goats, or an extra cow or two will turn a great deal of roughage into meat, and at the same time make much valuable fertilizer for the land.

\section{QUESTION-9}

Since the coming of the boll weevil, what is the farmer going to do for a money crop?

Answer-There are several crops, if wisely handled, from which the farmer can realize more money than from cotton; viz., corn, velvet beans, peanuts, sweet potatoes, and cow peas. If a paying market cannot be had for the raw product, they should be fed to stock, and turned into milk, meat, butter, eggs, lard, etc. There are but few, if any, better stockraising countries than ours. If the manure from these animals is carefully saved and returned to the land, practically all our fertilizer questions will be settled and our land will respond almost or quite equal to virgin soil. 


\section{QUESTION-10}

Should a renter or share-cropper attempt to carry out the above suggestions?

Answer-Yes, just as far as possible; he should set out trees, clean off ditch banks, make such repairs as he can, and in every way strive to leave the place in better condition than when he took possession. It will mean money in your pockets, aside from the great value of forming correct habits of living.

\section{QUESTION-11}

Will it pay a farmer to take an agricultural paper?

Answer-Yes, it is a necessity. He should not only take one or two good agricultural papers, but others as well. He must study markets, crops, weather, supply and demand, and a host of other things which affect him and his business. It is just as important to the farmer as to the merchant. In fact, it is the only way that either can keep abreast of the times.

\section{QUESTION-12}

Should the farmer attempt to have a pretty door-yard with flowers? Answer-Yes, by all means, for the reasons which follow:

(a) They are another form of God's silent messengers, and the "sweetest things $\mathrm{He}$ ever made and forgot to put a soul into."

(b) They are soothing and restful to the tired body and brain.

(c) We often send for the doctor, and take a lot of strong, disagreeable medicine when all we need is a bunch of beautiful flowers from loving hands.

(d) A love of flowers denote refinement and culture.

(e) Pretty dooryards and charming surroundings increase the value of property, and encourage the very best class of people to become our neighbors, 
